\title{
Anabases
}

ANABASES Traditions et réceptions de l'Antiquité

$23 \mid 2016$

Varia

\section{Francis LARRAN, Pisistrate à contretemps. Itinéraires anachroniques d'un tyran athénien}

\section{Geneviève Hoffmann}

\section{OpenEdition}

\section{Journals}

Édition électronique

URL : http://journals.openedition.org/anabases/5701

DOI : 10.4000/anabases.5701

ISSN : 2256-9421

\section{Éditeur}

E.R.A.S.M.E.

\section{Édition imprimée}

Date de publication : 2 mai 2016

Pagination : 319-321

ISSN : 1774-4296

\section{Référence électronique}

Geneviève Hoffmann, «Francis LARRAn, Pisistrate à contretemps. Itinéraires anachroniques d'un tyran athénien », Anabases [En ligne], 23 | 2016, mis en ligne le 02 mai 2016, consulté le 22 septembre 2020 URL : http://journals.openedition.org/anabases/5701 ; DOI : https://doi.org/10.4000/anabases.5701

Ce document a été généré automatiquement le 22 septembre 2020.

(c) Anabases 


\title{
Francis LARRAN, Pisistrate à contretemps. Itinéraires anachroniques d'un tyran athénien
}

\author{
Geneviève Hoffmann
}

\section{RÉFÉRENCE}

Francis LARRAN, Pisistrate à contretemps. Itinéraires anachroniques d'un tyran athénien Paris, L'Harmattan, 2014, 231 p.

25 euros/ ISBN 9782343044019

1 Ce n'est pas une nouvelle biographie de Pisistrate que nous présente Francis Larran (FL), mais une réflexion historiographique sur les Vies posthumes du tyran athénien. Dans son introduction (p.11-27), l'auteur marque les limites de l'histoire positiviste avant d'exposer sa méthode pour « extraire Pisistrate de la frise chronologique ». Il invite le lecteur à scruter les logiques anachroniques des récits qui, d'Hérodote à Elien, donnent vie à une autre histoire du tyran, celle qui prend sens dans le contexte des auteurs qui l'ont interrogée et interprétée.

Dans les trois parties qui composent l'ouvrage, sont exposées successivement les images de Pisistrate comme fondateur du politique, comme tyran idéal et comme modèle de sagesse.

3 La première partie : " Pisistrate, fondateur du politique ? ou l'histoire athénienne en question »(p.31-100), porte sur les différentes versions de la conquête du pouvoir. Dans le premier chapitre (p.35-55), FL interroge la logique des mises en abyme d'Hérodote et souligne combien le passage du tyran à Marathon, ignoré dans la suite de la tradition, était nécessaire à l'historien pour ancrer son récit à l'histoire athénienne. C'est la construction de l'empire athénien qui éclaire la prise du pouvoir en trois temps de Pisistrate. Puis FL relève les manipulations qu'impose Andocide à l'histoire dans son discours Sur les Mystères (chapitre II, p. 59-78). Le transfert de la bataille de Pallènè de 
546 à 510, en fait une victoire des démocrates sur les Pisistratides, dans le but d'opérer " un lessivage mémoriel "(p.64) et de démontrer que les oligarques unis aux démocrates sont le meilleur rempart contre la tyrannie. Dans le chapitre III (p. 81-100), l'histoire « pseudologique » d'Isocrate dans le Panathénaïque présente le tyran comme un démagogue rusé et violent pour faire apparaître la tyrannie comme une parenthèse dans l'histoire athénienne et convaincre de la nécessité de former moralement le peuple athénien.

4 La deuxième partie, "Pisistrate, tyran idéal ? ou l'ordre politique face au chaos de l'histoire ", est centrée sur la place accordée au tyran dans la pensée politique de Thucydide et d'Aristote (p. 103-162). En reprenant l'excursus vi, 53-59 de l'Histoire de la Guerre du Péloponnèse, (chapitre I, p.107-131), FL expose comment la tyrannie de Pisistrate et de ses fils permet à l'historien d'expliquer les raisons de la défaite athénienne. Tout comme la tyrannie était devenue intolérable en raison de son incapacité à préserver la concorde, la guerre du Péloponnèse a été perdue parce que les Athéniens n'ont pas su rester unis. Intitulé « Pisistrate au Lycée ou le temps de Cronos retrouvé ", le chapitre II de cette partie (p.135-162) s'appuie sur une formule d'Aristote dans la Constitution des Athéniens pour analyser une tradition historiographique dénuée de tout fondement historique, et dont le seul but est d'exprimer une vision partisane et nostalgique du passé, caractéristique des débats intellectuels $\mathrm{du} \mathrm{IV}^{\mathrm{e}}$ siècle. Aristote cherche à créer une figure exemplaire pour l'offrir comme source d'inspiration aux disciples du Lycée et aux hommes politiques.

5 La troisième partie intitulée : "Pisistrate, fidèle disciple ? ou la sagesse politique à l'épreuve du temps»(p.165-213) est une réflexion sur les qualités et les défauts associés à la mémoire de Pisistrate. Le tyran devient une figure morale dont le statut évolue en dépit de toute vraisemblance (chapitre I, p.169-192). Le couple SolonPisistrate est sorti du corset chronologique pour évoluer hors du temps et démontrer le lien naturel entre la philosophie et la politique. La prise de Salamine aux Mégariens est un tel enjeu historiographique depuis l'Antiquité que FL parle de " cacophonie » (p. 169). Si pour les uns, l'île a été arrachée aux Mégariens par Solon seul, pour d'autres elle l'a été par Solon avec l'aide de Pisistrate. Tout en donnant au tyran la stature du bon citoyen, Aristote se refuse, quant à lui, à l'associer au Sage Solon.

6 Le dernier chapitre (p.195-213) : "Quand Thémistocle rencontre Pisistrate ou l'anachronisme comme outil de penser chez Élien » renvoie à un passage de l'Histoire Variée selon lequel Thémistocle encore enfant aurait rencontré le tyran. Elien instrumentalise l'anecdote comme " outil à penser » (p.210), pour faire œuvre morale et surprendre son lecteur, tout en ne s'interdisant pas l'allusion érudite. Il s'inscrit ainsi dans les débats de la Seconde Sophistique sur la place respective de Solon, de Pisistrate et de Thémistocle dans l'histoire athénienne.

7 La conclusion : « Lire Pisistrate au présent pour le comprendre au passé » (p. 217-225) insiste sur la contribution du tyran à la réflexion politique. Pisistrate voyage à diverses époques et ses mues anachroniques s'expliquent par les débats du temps. Son histoire est déformée pour être mise au service de la mémoire tandis que la vérité factuelle est soumise à l'impératif moral. Cette récupération est fondée sur la volonté de faire œuvre utile et la conviction que des leçons peuvent être tirées du passé, l'homme étant toujours mu par les mêmes passions. Comme pour FL, l'anachronisme est une pratique intellectuelle incontournable, il s'explique sur ses motivations et sur le " présentisme " pour faire de « son » Pisistrate un miroir du début du xxI siècle. 
8 Par sa forme, ce livre garde trace des articles qui le composent et qui ont été publiés dans des revues scientifiques depuis 2012. Il aurait gagné à être plus synthétique. Les titres surprenants et pour le moins alambiqués contribuent à étourdir le lecteur. Toutefois, ces critiques formelles ne sauraient masquer l'intérêt de la démarche suivie. Cette recherche, portée par une analyse rigoureuse des textes, substitue à l'histoire logique et continue du tyran une autre figure de Pisistrate, une figure non plus historique mais mémorielle dont les fondements mériteraient d'être encore mieux développés. Certes, personne n'est dupe de l'histoire positiviste et on sait que « Pisistrate ne pourrait s'extraire du passé pour venir, indemne, jusqu'à nous » (p.15), mais après cet inventaire, sa figure historique semble s'évanouir à jamais ou plutôt elle se décompose en une galerie de portraits qui imposent au premier chef la lecture des sources.

\section{AUTEURS}

\section{GENEVIÈVE HOFFMANN}

Université de Picardie Jules Verne genevieve.hoffmann@wanadoo.fr 